\title{
ELABORATING ON INTERNET ADDICTION AND CYBERCHONDRIA - RELATIONSHIPS, DIRECT AND MEDIATED EFFECTS
}

\author{
ELIZA IVANOVA \\ Department of General, Experimental, and Genetic Psychology, \\ Sofia University "St. Kliment Ohridski", \\ 15 Tsar Osvoboditel Blvd., Sofia, Bulgaria \\ E-mail address: elizaxivanova@gmail.com

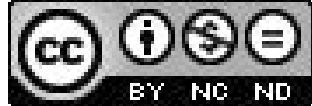 \\ SONYA KARABELIOVA \\ Department of General, Experimental, and Genetic Psychology, \\ Sofia University "St. Kliment Ohridski", \\ 15 Tsar Osvoboditel Blvd., Sofia, Bulgaria \\ E-mail address: karabeliovasonya@gmail.com
}

\begin{abstract}
The present paper focuses on the effects of personality traits on the levels of Internet addiction and cyberchondria and their consequent effects on well-being. For the purposes of the research, mediation analyses were carried out, clarifying the influence of personality traits on well-being mediated by Internet addiction, cyberchondria and anxiety aroused by online health information seeking. It was established that Neuroticism leads to decreased well-being through the mediating influence of health anxiety, escalation and persistence of health concerns. Health anxiety is a mediator in the relationship between Openness to Experience and well-being. It was established that low levels of Agreeableness and Conscientiousness, and high levels of Openness, and Neuroticism, influence Internet addiction, which in turn leads to decreased well-being. Furthermore, we established the mediated influence of Internet addiction on the tendency for cyberchondria and health anxiety through using the Internet for health information and judgment biases.
\end{abstract}

Keywords: Internet addiction, cyberchondria, personality traits, well-being, mediation analysis.

\section{INTRODUCTION}

The Internet is constantly reaching new areas of people's lives and is thus becoming a more and more significant aspect of everyday functioning. There is a predisposition for users to spend increasing amounts of time online instead of in real-life activities. Not only do people use the Internet for online communication and entertainment, but they also approach it as a source of information on a 
myriad of topics, including health. Online sources of health information are not always reliable and do not necessarily provide accurate information, which might lead to disinformation, confusion, and anxiety. The purpose of the present paper is to present the results of an empirical study of the relationships between Internet addiction, cyberchondria, their influence on well-being, and how personality traits predict these contemporary psychological conditions.

\section{INTERNET ADDICTION}

The Internet stimulates brain activity, affecting mood, and potentially - behaviour, by means of interesting content, low price, easy access, convenience, visual stimulation, autonomy, and anonymity (Greenfield, 1999). The intensive advance of the Internet in contemporary life and the expansion of the entertainment, facilitation, education, information, and so on, increases its potential for becoming an object of addiction. The negative consequences of addictive behaviours usually affect the main spheres of a person's life - relationships, work, health, and finances. Due to the lack of formally accepted criteria for Internet addiction, researchers in the field use different approaches, definitions, and terminology to describe the problem. We adhere to Kimberly Young's (1996) theory of Internet addiction, which is based on an analogy with pathological gambling. The author defines Internet addiction as an impulse control disorder and adapts eight criteria for pathological gambling from DSM-IV. She chooses those diagnostic criteria which define Internet addiction and contrasts them with normal Internet use. Positive answers to five of the eight diagnostic criteria indicate Internet addiction: 1) thoughts about Internet activity; 2) the need for constant increase in the time spent online; 3 ) unsuccessful efforts for control over the use; 4 ) the negative affects resulting from cutting down or stopping the use; 5) staying online longer than intended; 6) jeopardising an important job, relationship, educational or career opportunity; 7) lying about the time spent online; 8) using the Internet for escaping from problems and dysphoric moods.

Internet addiction is frequently manifested in a distorted perception of time, which impedes the execution of important activities in the users' lives. Work, studies, personal life, family, and social contacts are neglected to differing extents (Young, 2007).

Researchers maintain the view that spending a considerable part of one's time online leads to a reduction in real-life contacts and a decline in the quality of relationships (Amichai-Hamburger, \& Ben-Artzi, 2003; Caplan, 2003). Satisfying relationships protect the user against stressors, and therefore, adolescents with high quality relationships are happier and socially more competent (Valkenburg, \& Peter, 2007). Results from research establishing a connection between Internet addiction and depression support this view (Morrison, \& Gore, 2010; Caplan, 2003). Furthermore, Michele Ybarra, Cheryl Alexander, and Kimberly Mitchell (2005) found that spending more than three hours a day online was linked to the possibility of depressive symptoms in adolescents. K. Young (1998) registered that $56 \%$ of the participants in her study who cover the diagnostic criteria for Inter- 
net addiction were also socially isolated. Users usually try to alleviate loneliness, depression, strain, and problems through various online applications (MorahanMartin, 2005; Young, 2007; Greenfield, 1999). This sense of shelter which people associate the Internet with is one of the reasons for adding to the emotional element of addiction - users try to stimulate certain positive feelings, to avoid negative ones, and to escape difficult situations by blocking their thoughts through Internet use. In some cases people try to substitute problematic aspects of their lives for online activities (real life relationships - for online relationships or sex with a partner - for cybersex and Internet pornography) (Young, 2007).

\section{HEALTH ANXIETY AND CYBERCHONDRIA}

The cognitive-behavioural approach to hypochondria defines it as an acute form of health anxiety associated with a tendency for erroneous interpretation of bodily sensations and of ambivalent health information from different sources towards having a serious illness (Salkovskis, Rimes, Warwick, \& Clark, 2002). This view explains health anxiety with dysfunctional cognitions, which stimulate health concerns, despite the presence of information which disproves them. Health anxiety can also be defined as unfounded health concerns for the personal health, in the absence of pathology, or excessive worries, when there is an insignificant health problem (Lucock, \& Morley, 1996, as cited in Gravatt, \& Brown, n.d.). People who experience high health anxiety strive to diminish their worries by applying strategies, such as looking for health information online. Contrary to their intention, anxious people aggravate their anxiety, because they focus on the disturbing information they find, and are unable to integrate the positive or nonserious explanations.

Steven Gravatt and Michael Brown (n.d.) record that people with high health anxiety are those who seek health information online more, and as a result feel more concerned. Online health information has a significant potential influence on the user's decisions to visit a doctor, to change their medication, to take care of their health in different ways (diet, exercise, healthy way of life, etc.) (White, \& Horvitz, 2009a). On the one hand, the Internet is a valuable instrument which provides social support and knowledge, but, on the other hand, precisely the information gathered from others might have a harmful effect on one's anxiety. Inappropriate or unreliable information might push a person to self-diagnose or decide on a treatment for their alleged condition. Michele Ybarra and Michael Suman (2006) established that two of every five respondents try to diagnose themselves using the Internet and one in every three tries to treat a health problem after reading about it online.

Research attests that people rarely use a combination of words and phrases when looking for information, which leads to less accurate and relative results (Eysenbach, \& Köhler, 2002). Usually people click on some of the first results, paraphrasing their search word and rarely looking through the second page of results (Morahan-Martin, 2004, as cited in Atkinson, Saperstein, \& Pleis, 2009; Eysenbach, \& Köhler, 2002). The most common instrument for health informa- 
tion search are search engines like Google, Yahoo!, Live Search, Bing, and not specialized health portals (Eysenbach, \& Köhler, 2002; Ybarra, \& Suman, 2006; White, \& Horvitz, 2009a; Pletneva, Cruchet, Simonet, Kajiwara, Boyer, 2010; Muse, McManusa, Leunga, Meghrebliana, \& Williams, 2011). The disadvantage of using general search engines is the fact that they generate results from all kinds of sources (reliable or not), usually arranged by number of clicks following a search with a certain key word, and not by accuracy, reliability, and relevance. Ryen White and Eric Horvitz (2009a) established that a web search for medical information on nonspecific symptoms generates lots of results presenting grave and rare conditions. Consequently, around $70 \%$ of users change the topic of their search and turn their attention to some of the serious illnesses associated with the initial symptom. People expose themselves to excessive information on life-threatening chronic conditions, without having medical education, which naturally might increase their health anxiety.

R. White and E. Horvitz (2009a) define cyberchondria as the "unfounded escalation of concerns about common symptomatology, based on the review of search results and literature on the Web" (White, \& Horvitz, 2009a, p. 1). Changing the focus of a web search from a nonspecific symptom to a serious illness represents the escalation of concerns, which is an important aspect of cyberchondria. The initial escalation may lead to persistence of concerns - short- or long-term elevation of the levels of health anxiety, which consumes time, might impair the typical activities of the person and might be a reason for a check-up. Judgment biases play a significant role in the mechanism of cyberchondria. Availability bias and baserate neglect are activated in the process of interpreting health information following a web search. In their research the two authors use not only a questionnaire for cyberchondria, but they also analyse the logs from the web searches of participants. R. White and E. Horvitz (2012) recorded that in $95 \%$ of the cases when the search starts with a medical condition and not a symptom, the person has already been diagnosed by a doctor, or has searched for health information previously and the condition in question appeared in the results.

Half of the respondents in a research, carried out by Natalia Pletneva et al. (2010), claimed not to have experienced elevated anxiety as a consequence of online health search, as opposed to $30 \%$ who declared they did. In comparison, R. White and E. Horvitz (2009b) recorded that $40 \%$ of users felt more anxious after searching for health information online, while $50 \%$ claimed their health anxiety decreased. Susanne Baumgartner and Tilo Hartmann (2011) established that anxious people use the Internet for health information more than others.

Anxiety rises as a result of searching for health information online, which may influence the interpretation of what is read, or in other words may lead to judgment biases in the terminology of R. White and E. Horvitz (2009a). Trait anxiety can also influence the levels of health anxiety following a web search. Anxious people feel relief more rarely after looking for health information, than people with low levels of health anxiety. Respondents can be reassured by appropriate information, which comes from a reliable source or by the summarised information from various websites. Rationalisation of the initial stress aroused by coming 
across information about a serious illness and realisation of its low probability, as well as gaining knowledge which grants confidence, are methods for decreasing health anxiety.

\section{OBJECTIVES}

The purpose of the study is to investigate the relationships between Internet addiction, cyberchondria, well-being and personality traits. Therefore, we focus on establishing the direct and indirect effects between Internet addiction, anxiety aroused by online health searches, cyberchondria, eudaimonic well-being, psychological well-being, and personality traits.

On the basis of the objective of the empirical study, the following hypotheses were formulated:

H1: Neuroticism will be a predictor for anxiety aroused by online health information seeking and cyberchondria.

H2: Low Conscientiousness will be a predictor for Internet addiction.

H3: Neuroticism will be negatively associated with well-being, but the relationship will be mediated by Internet addiction, health anxiety, escalation, and persistence of health concerns.

H4: Internet addiction will have an effect on anxiety aroused by online health information seeking, escalation, and persistence of concerns via mediators judgment biases and extent of online health information seeking.

\section{METHOD}

\section{Participants}

The questionnaire was completed by 615 participants, aged between 13 and 70 (34\% were up to 20 years old, $31 \%$ were between 21 and 25 , and $35 \%$ were over 25 ). The respondents were $40 \%$ male and $60 \%$ female. As far as marital status is concerned, only $27 \%$ of participants were either married or lived with a partner, whereas $73 \%$ lived on their own. The large difference between the two groups could be attributed to the prevalence of young respondents who were still students and who presumably had not yet started a family. According to the place of residence, it was registered that $70 \%$ lived in the capital of Bulgaria - Sofia. The respondents working at the moment of participating in the study were $53 \%$. As for education, $58 \%$ declared having a diploma for secondary education, while $42 \%$ stated they had higher education. The group of people with higher education incorporated $20 \%$ with master's degree, $17 \%$ with bachelor's degree and $2 \%$ with a doctor's degree. There were more respondents with secondary education due to the large number of students in the study.

\section{Measures}

Internet addiction. The Internet Addiction Test (IAT), designed by Young (1998, as cited in Widyanto, \& McMurran, 2004), consists of 20 items describing behaviours linked to different aspects of Internet addiction. For the purpose of the pre- 
sent research, we used a five-point Likert scale ranging from 1 ("Never") to 5 ("Always"). The score on the IAT ranges from 20 to 100. K. Young defined three groups of users according to the score: 20-39 - an average user without control issues; 40-69 - a user with problems; 70-100 - a user with significant problems due to uncontrolled Internet use.

Health anxiety. The second questionnaire measures anxiety aroused by online health information seeking (Gravatt, \& Brown, n.d.). It consists of 14 items concerning the use of Internet for health information, as well as the cognitions and affects provoked by that use. The responses were measured with a five-point Likert scale ranging from 1 ("Strongly disagree") to 5 ("Strongly agree"). The authors formed three factors: belief that online health information is accurate; extent of online health information seeking; anxiety aroused by online health information seeking.

Cyberchondria. The questions concerning cyberchondria were taken from R. White and E. Horvitz's (2009a) research. We included 17 items concerning users' perceptions of health information on the Internet, their experience with searching the web for health information, and the influence of the Internet on their health concerns. The three themes measured by the questionnaire are escalation of concerns, persistence of concerns and judgment biases. A few different response scales were used: a dichotomous scale with yes/no answers; Likert type scales ranging from 1 ("Never") to 5 ("Always") and from 1 ("I do not worry at all") to 5 ("I worry excessively").

Eudaimonic well-being. The questionnaire measuring eudaimonic well-being was designed by Alan Waterman, Seth Schwartz, Byron Zamboanga, Russell Ravert, Michelle Williams, Bede Agocha, Su Yeong Kim, and Brent Donnellan (2010). The authors define eudaimonic well-being as incorporating subjective as well as objective elements. Subjective elements are feelings of personal expressiveness and objective elements are all behaviours directed at self-realisation, through the recognition and development of personal potential, so that one leads a meaningful life. The questionnaire is comprised of 21 items. The scale we applied was a five-point Likert one, ranging from 1 ("Strongly disagree") to 5 ("Strongly agree").

Psychological well-being. A short version of the Ryff scales of psychological well-being, adapted for Bulgarian conditions (Silgidgyan, Karabeliova, \& Zankova, 2008), was used in the study. The questionnaire consists of 18 items measured with a six-point Likert scale (1 - "Strongly disagree"; 6 - "Strongly agree"). The six dimensions of psychological well-being are Autonomy, Environmental Mastery, Personal Growth, Positive Relations with Others, Purpose in Life, and Self-Acceptance.

Personality traits. The Mini-IPIP (Donnellan, Oswald, Baird, \& Lucas, 2006) questionnaire was applied for measuring personality traits according to the Big Five model. The instrument is comprised of 20 items and is a short version of Lewis Goldberg's IPIP-FFM (1999). Each of the five factors - Neuroticism, Extraversion, Agreeableness, Conscientiousness, and Openness to Experience is represented by four items from the inventory. Participants indicated their answer on a five-point scale ranging from 1 - "It doesn't apply to me all" to 5 - "It completely applies to me". 


\section{RESULTS AND DISCUSSION}

The data gathered with the questionnaire were analysed via the statistical program SPSS. For the purposes of the research regression and mediation analyses were carried out. On the basis of the established results we can draw conclusions regarding the relationships between the studied phenomena.

\section{Regression analysis}

The results from the stepwise regression analyses with the five personality traits as predictors and Internet addiction, health anxiety aroused by online health information search, escalation, and persistence of concerns indicating cyberchondria as outcome variables are shown on Figure 1. Conscientiousness $(\beta=-0.313)$ and Neuroticism $(\beta=0.189)$ were registered as significant predictors for Internet addiction. Low levels of Conscientiousness and high levels of Neuroticism accounted for 15\% of the variance in Internet addiction $\left(R^{2}=0.151\right)$. Openness $(\beta=-0.142)$ and Neuroticism $(\beta=0.216)$ predicted significantly anxiety aroused by online health information seeking. Rigidness and emotional instability are predispositions for experiencing health anxiety, stimulated by information on the Internet. Nevertheless these personality dimensions explain only $6.6 \%$ of the variance in the outcome variable $\left(R^{2}=0.066\right)$. Neuroticism $(\beta=0.202)$ and Conscientiousness $(\beta=-0.123)$ significantly predict escalation of health concerns as an indicator of cyberchondria.

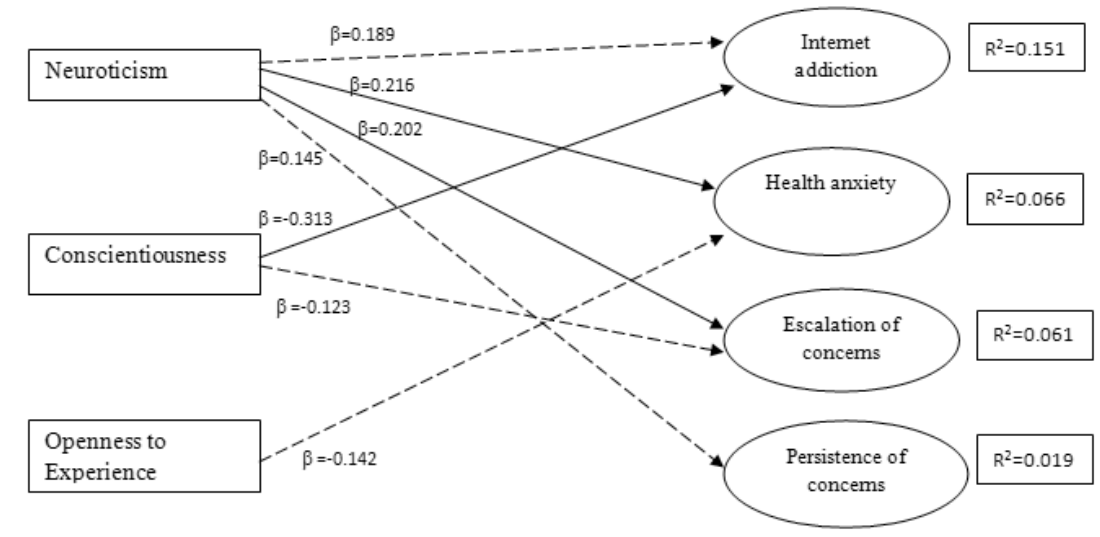

Fig.1. Significant effects of personality traits on Internet addiction, anxiety aroused by online health information seeking, escalation, and persistence of health concerns

Source: Own research.

High levels of Neuroticism and low levels of Conscientiousness account for 6\% of the variance in escalation of concerns as a result from looking for health information on the Internet $\left(R^{2}=0.061\right)$. The other significantly affected by Neuroticism aspect of cyberchondria is persistence of concerns $(\beta=0.145)$. It should be pointed out that Neuroticism explains merely $2 \%$ of the variance in persistence of the already aroused health concerns. 
We can conclude that our first hypothesis is not only confirmed but also expanded, because we found that Neuroticism is a predictor for anxiety aroused by online information seeking and cyberchondria (escalation and persistence of concerns), on the one hand, but it also predicts Internet addiction.

Furthermore, the second hypothesis, which is rooted in the definition of Internet addiction as an impulse control disorder (Young, 1996), was also confirmed by means of our findings that low Conscientiousness predicts Internet addiction.

\section{Mediation analysis}

In order to unveil the relationships between the studied phenomena in better detail, we applied mediation analysis. The introduction of a third variable mediating the effect of the independent on the dependent variable is done to add more explanatory power to the proposed models. Figure $2-2$ ) illustrates single mediation (MacKinnon, \& Dwyer, 1993). In this model variations in the independent variable are associated with significant variations in the mediating variable (path $a$ ). Variations in the mediator are associated with variations in the dependent variable (path b). The indirect effect of the independent variable on the dependent variable is the product $a b$. The total effect of the independent variable on the dependent variable is path $c$ (figure $2-1$ )) and it can be represented through the algebraic expression $c$ $=c^{\prime}+a b$, where $c^{\prime}$ is the direct effect and $a b$ is the indirect effect of the independent variable on the dependent variable through the mediator.

We applied Kristopher Preacher and Andrew Hayes's (2008) procedure for multiple mediation. Their approach to testing significance of the mediated effect is by using bootstrapping in order to obtain confidence intervals for the indirect effect. This method

1)

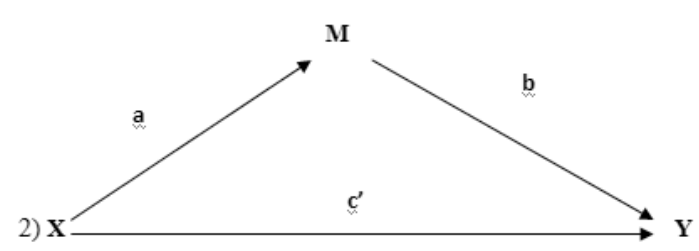

is characterized by repeat-

edly drawing samples from Fig. 2. Graphic expression of 1) the direct effect of $X$ on $Y$ and 2) the data (usually from 1000 the indirect effect of $X$ on $Y$ when a mediator is introduced to 5000 different samples) Source: Preacher, \& Hayes, 2008.

for which the values of $a, b$,

and $a b$ are calculated. The sampling provides values from which the standard error of the indirect effect could be derived. The method is not based on the assumption for normal distribution, which leads to more accurate results in comparison with other methods such as the Sobel test (Sobel, 1982), which are more appropriate for very large samples. The bootstrapping procedure presents the researcher with the opportunity to detect indirect effects which are not normally distributed - since the value of the mediated effect is a product of two coefficients, it is not always normally distributed. Bootstrapping leads to unstandardised coefficients which cannot be compared. The significance of the mediated effect is determined by 
confidence intervals. In the present study we used the A. Hayes's (Indirect) SPSS custom dialog of the macro for multiple mediation (Hayes, n.d.).

Regarding the assumption that Neuroticism leads to lower levels of well-being through the mediating effect of Internet addiction, anxiety aroused by online health information seeking and cyberchondria (measure by escalation and persistence of concerns), the following results were registered (see Table 1).

In mediation analyses with Neuroticism as an independent variable, eudaimonic well-being as a dependent variable, and Internet addiction as a mediator, we registered significant unstandardised coefficients. Therefore, we could infer significant direct effects of Neuroticism on Internet addiction $(a=0.795 ; p=0.000)$, and of Internet addiction on well-being $(b=-0.102 ; p=0.000)$, as well as a significant total effect of Neuroticism on well-being ( $\left.c^{\prime}=-0.468 ; p=0.000\right)$. The estimated indirect effect of Neuroticism on eudaimonic well-being mediated by Internet addiction is negative $(a b=-$ 0.0806; $\mathrm{SE}=0.0291$ ). On the basis of bootstrapping with 5000 samples from the data file, a confidence interval defining the significance of the mediated effect has been generated $[-0.1469 ;-0.0306]$. The estimated mediated effect lies in the middle between the lower and the upper limit of the confidence interval. Since zero does not lie within the interval range, we could arrive at the conclusion that the indirect effect of the mediator - Internet addiction is significant. The indirect effect falls into this confidence interval with $95 \%$ certainty, meaning that the zero hypothesis: $a b=0$ is rejected. Neuroticism indirectly leads to lower eudaimonic well-being through the mediator Internet addiction. The proposed model explains around 7\% of the variance in eudaimonic wellbeing $\left(R^{2}=0.067\right)$, which is not a lot, but still the relationship is significant.

All mediation models included in Table 1 have significant direct and total effects $\left(a, b, c, c^{\prime} ; p<0.05\right)$ and significant indirect effects as it can be traced by the limits of the confidence interval which do not include zero.

Internet addiction mediates the relationship between Neuroticism on the one hand and the psychological well-being aspects: autonomy, environmental mastery, and purpose in life, on the other hand. The aspect of cyberchondria - escalation of concerns mediated one relationship - between Neuroticism and the scale for psychological well-being - purpose in life. It was found that anxiety aroused by online health information search mediated most of the relationships between Neuroticism and well-being measures (eudaimonic well-being, autonomy, personal growth and self-acceptance). All of the noted mediation effects were negative, meaning that the personal trait Neuroticism is a predictor for Internet addiction, anxiety aroused by online health information search, and escalation of concerns as an aspect of cyberchondria, which in turn are predictors for decreased eudaimonic well-being and certain aspects of psychological well-being.

In summary, we did not register significant mediated influence of Neuroticism on one of the scales of psychological well-being - positive relations with others. On the other hand, the aspect of cyberchondria - persistence of concerns was not found to have a specific indirect effect on any of the measures of well-being. Therefore, the third hypothesis that Neuroticism would be negatively associated with well-being, but the relationship would be mediated by Internet addiction, health anxiety, escalation and persistence of health concerns was partly confirmed. 
Tab. 1. Significant indirect effects with independent variable Neuroticism and dependent variables eudaimonic well-being and the scales of psychological well-being

\begin{tabular}{|c|c|c|c|c|c|}
\hline \multirow{2}{*}{$\begin{array}{l}\text { Independent variable - me- } \\
\text { diator - dependent variable }\end{array}$} & \multirow{2}{*}{$\begin{array}{c}\text { Esti- } \\
\text { mated } \\
\text { specific } \\
\text { indirect } \\
\text { effect }\end{array}$} & \multirow{2}{*}{$\begin{array}{l}\text { Stan- } \\
\text { dard } \\
\text { error }\end{array}$} & \multicolumn{2}{|c|}{$\begin{array}{l}95 \% \text { confidence } \\
\text { interval } \\
\end{array}$} & \multirow{2}{*}{$\begin{array}{c}\text { Expla- } \\
\text { ined } \\
\text { varian- } \\
\text { ce }\left(\mathrm{R}^{2}\right)\end{array}$} \\
\hline & & & $\begin{array}{l}\text { Lower } \\
\text { limit }\end{array}$ & $\begin{array}{c}\text { Upper } \\
\text { limit }\end{array}$ & \\
\hline $\begin{array}{l}\text { Neuroticism - Internet addic- } \\
\text { tion - eudaimonic well-being }\end{array}$ & -0.0806 & 0.0291 & -0.1469 & -0.0306 & 0.067 \\
\hline $\begin{array}{l}\text { Neuroticism - Internet addic- } \\
\text { tion - purpose in life }\end{array}$ & -0.0349 & 0.0108 & -0.0598 & -0.0164 & 0.091 \\
\hline $\begin{array}{l}\text { Neuroticism - Internet addic- } \\
\text { tion - autonomy }\end{array}$ & -0.0338 & 0.0106 & -0.0591 & -0.0162 & 0.104 \\
\hline $\begin{array}{l}\text { Neuroticism - Internet addic- } \\
\text { tion - environmental mastery }\end{array}$ & -0.0499 & 0.0123 & -0.0781 & -0.0295 & 0.211 \\
\hline $\begin{array}{l}\text { Neuroticism - escalation of } \\
\text { concerns - purpose in life }\end{array}$ & -0.0135 & 0.0100 & -0.0475 & -0.0034 & 0.067 \\
\hline $\begin{array}{l}\text { Neuroticism - health anxiety } \\
\text { - eudaimonic well-being* }\end{array}$ & -0.1131 & 0.0436 & -0.2161 & -0.0417 & 0.069 \\
\hline $\begin{array}{l}\text { Neuroticism - health anxiety } \\
\text { - environmental mastery * }\end{array}$ & -0.0252 & 0.0136 & -0.0570 & -0.0017 & 0.169 \\
\hline $\begin{array}{l}\text { Neuroticism - health anxiety } \\
\text { - autonomy * }\end{array}$ & -0.0468 & 0.0159 & -0.0831 & -0.0204 & 0.111 \\
\hline $\begin{array}{l}\text { Neuroticism - health anxiety } \\
\text { - personal growth* }\end{array}$ & -0.0506 & 0.0168 & -0.0892 & -0.0229 & 0.050 \\
\hline $\begin{array}{l}\text { Neuroticism - health anxiety } \\
\text { - self-acceptance* }\end{array}$ & -0.0315 & 0.0212 & -0.0653 & -0.0069 & 0.236 \\
\hline
\end{tabular}

Mediation models marked with * apart from specific indirect effect of the indicated mediator, have also total indirect effect of all mediators introduced to the equation.

Source: Own research.

Table 2 lists the significant mediated effects of the personal trait Openness to Experience on eudaimonic and psychological well-being with mediators Internet addiction, escalation of concerns and anxiety aroused by online health information seeking. The indirect effects of the mediators are significant, because zero does not lie within their confidence intervals with a $95 \%$ probability, which attests mediation.

Series of multiple mediation analyses were carried out with the purpose of establishing the indirect influence of Openness on well-being with mediators the composite variables from the questionnaire for health anxiety, stimulated by Internet use - anxiety aroused by online health information seeking, belief that online health information is accurate, and extent of online health information seeking. As reported in Table 2 only anxiety aroused by online health information seeking (health anxiety) demonstrates significant specific indirect effects. Nevertheless, we also established significant total indirect effects of all three mediators in the listed mediation relationships, even if the other two mediators - "belief" and "extent" do not have significant specific indirect effects. 
It was established that Openness influenced autonomy, environmental mastery, personal growth, purpose in life and self-acceptance, mediated by anxiety aroused by online health information seeking. Increased levels of Openness were associated with lower tendency for health anxiety stimulated by online information and vice versa - people with more conventional thinking were more inclined to experience heightened health anxiety when looking for information online. This is probably due to their propensity to trust what they read, while those with more developed abstract and non-traditional ways of thinking are more likely not to believe everything they come across on the Internet and to continue to look for information from various sources. On the other hand, health anxiety is negatively connected with well-being. Increased health anxiety leads to a decrease in five of the six aspects of psychological well-being (with the exception of positive relations with others).

Tab. 2. Significant indirect effects with independent variable Openness and dependent variables eudaimonic well-being and the scales of psychological well-being

\begin{tabular}{|c|c|c|c|c|c|}
\hline \multirow{2}{*}{$\begin{array}{l}\text { Independent variable - media- } \\
\text { tor - dependent variable }\end{array}$} & \multirow{2}{*}{$\begin{array}{c}\text { Esti- } \\
\text { mated } \\
\text { specific } \\
\text { indirect } \\
\text { effect }\end{array}$} & \multirow{2}{*}{$\begin{array}{l}\text { Stan- } \\
\text { dard } \\
\text { error }\end{array}$} & \multicolumn{2}{|c|}{$\begin{array}{c}95 \% \text { confidence } \\
\text { interval }\end{array}$} & \multirow{2}{*}{$\begin{array}{l}\text { Expla- } \\
\text { ined } \\
\text { variance } \\
\left(\mathrm{R}^{2}\right)\end{array}$} \\
\hline & & & $\begin{array}{l}\text { Lower } \\
\text { limit }\end{array}$ & $\begin{array}{l}\text { Upper } \\
\text { limit }\end{array}$ & \\
\hline $\begin{array}{l}\text { Openness - Internet } \\
\text { addiction - eudaimonic well- } \\
\text { being }\end{array}$ & -0.0515 & 0.0266 & -0.1105 & -0.0054 & 0.083 \\
\hline $\begin{array}{l}\text { Openness - Internet } \\
\text { addiction - environmental } \\
\text { mastery }\end{array}$ & -0.0261 & 0.0478 & -0.0549 & -0.0002 & 0.110 \\
\hline $\begin{array}{l}\text { Openness - health anxiety - } \\
\text { autonomy* }\end{array}$ & 0.0443 & 0.0166 & 0.0183 & 0.0856 & 0.060 \\
\hline $\begin{array}{l}\text { Openness - health anxiety - } \\
\text { environmental mastery * }\end{array}$ & 0.0332 & 0.0146 & 0.0101 & 0.0686 & 0.033 \\
\hline $\begin{array}{l}\text { Openness - health anxiety - } \\
\text { personal growth* }\end{array}$ & 0.0326 & 0.0139 & 0.0111 & 0.0674 & 0.110 \\
\hline $\begin{array}{l}\text { Openness - health anxiety - } \\
\text { purpose in life* }\end{array}$ & 0.0259 & 0.0384 & 0.0051 & 0.0598 & 0.015 \\
\hline $\begin{array}{l}\text { Openness - health anxiety - } \\
\text { self-acceptance* }\end{array}$ & 0.0367 & 0.0152 & 0.0130 & 0.0766 & 0.065 \\
\hline
\end{tabular}

Mediation models marked with * apart from specific indirect effect of the indicated mediator, have also total indirect effect of all mediators introduced to the equation.

Source: Own research.

For the purpose of investigating the indirect effects of Conscientiousness on well-being, single mediation analyses with a mediator Internet addiction and multiple mediation analyses with mediators: anxiety aroused by online health information seeking, belief that online health information is accurate, and extent of online health information seeking and separately with mediators: escalation and persistence of concerns, were carried out. The significant results are shown in Table 3. 
The listed indirect effects are significant, since with 95\% certainty they cannot be zero (see the confidence intervals), therefore, we could infer mediation. No significant indirect effects were registered regarding the three scales from the questionnaire for anxiety aroused by online health information seeking and for the aspects of cyberchondria - persistence of concerns and judgement biases.

Tab. 3. Significant indirect effects with independent variable Conscientiousness and dependent variables eudaimonic well-being and the scales of psychological well-being

\begin{tabular}{|c|c|c|c|c|c|}
\hline \multirow{2}{*}{$\begin{array}{l}\text { Independent variable - mediator - } \\
\text { dependent variable }\end{array}$} & \multirow{2}{*}{$\begin{array}{c}\text { Esti- } \\
\text { mated } \\
\text { specific } \\
\text { indirect } \\
\text { effect }\end{array}$} & \multirow{2}{*}{$\begin{array}{l}\text { Stan- } \\
\text { dard } \\
\text { error }\end{array}$} & \multicolumn{2}{|c|}{$\begin{array}{l}95 \% \text { confidence } \\
\text { interval }\end{array}$} & \multirow{2}{*}{$\begin{array}{l}\text { Explained } \\
\text { variance } \\
\left(\mathrm{R}^{2}\right)\end{array}$} \\
\hline & & & $\begin{array}{l}\text { Lower } \\
\text { limit }\end{array}$ & $\begin{array}{l}\text { Upper } \\
\text { limit }\end{array}$ & \\
\hline $\begin{array}{l}\text { Conscientiousness - Internet } \\
\text { addiction - eudaimonic well-being }\end{array}$ & 0.0907 & 0.0410 & 0.0170 & 0.1806 & 0.084 \\
\hline $\begin{array}{l}\text { Conscientiousness - Internet } \\
\text { addiction - autonomy }\end{array}$ & 0.0583 & 0.0147 & 0.0313 & 0.0893 & 0.054 \\
\hline $\begin{array}{l}\text { Conscientiousness - Internet } \\
\text { addiction - environmental mastery }\end{array}$ & 0.0628 & 0.0150 & 0.0365 & 0.0961 & 0.200 \\
\hline $\begin{array}{l}\text { Conscientiousness - Internet addiction } \\
\text { - positive relations with others }\end{array}$ & 0.0305 & 0.0140 & 0.0044 & 0.0588 & 0.028 \\
\hline $\begin{array}{l}\text { Conscientiousness - Internet } \\
\text { addiction - purpose in life }\end{array}$ & 0.0388 & 0.0141 & 0.0133 & 0.0695 & 0.110 \\
\hline $\begin{array}{l}\text { Conscientiousness - Internet } \\
\text { addiction - self-acceptance }\end{array}$ & 0.0408 & 0.0146 & 0.0144 & 0.0719 & 0.044 \\
\hline $\begin{array}{l}\text { Conscientiousness - escalation of } \\
\text { concerns - autonomy * }\end{array}$ & 0.0170 & 0.0084 & 0.0040 & 0.0380 & 0.045 \\
\hline $\begin{array}{l}\text { Conscientiousness - escalation } \\
\text { of concerns - environmental } \\
\text { mastery* }\end{array}$ & 0.0124 & 0.0072 & 0.0016 & 0.0312 & 0.174 \\
\hline $\begin{array}{l}\text { Conscientiousness - escalation of } \\
\text { concerns - purpose in life }\end{array}$ & 0.0149 & 0.0080 & 0.0030 & 0.0351 & 0.115 \\
\hline $\begin{array}{l}\text { Conscientiousness - escalation of } \\
\text { concerns - self-acceptance * }\end{array}$ & 0.0197 & 0.0088 & 0.0060 & 0.0413 & 0.056 \\
\hline
\end{tabular}

Mediation models marked with * apart from specific indirect effect of the indicated mediator, have also total indirect effect of all mediators introduced to the equation.

Source: Own research.

The personality trait Conscientiousness had indirect effects on well-being through the mediators Internet addiction and escalation of concerns as an aspect of cyberchondria. Internet addiction mediated the influence of Conscientiousness on eudaimonic well-being and psychological well-being. Low Conscientiousness, which finds expression in lack of direction, organisation and discipline, logically has an effect on Internet addiction, due to the fact that Internet addiction is most commonly defined as an impulse control disorder (Young, 1996). On the other hand, the findings of negative relationships between Internet addiction and dif- 
ferent aspects of well-being are in line with previous studies (Caplan, 2002, 2003; Morahan-Martin, \& Schumacher, 2000; Armstrong, Phillips, \& Saling, 2000; Young, 1998; Young, \& Rodgers, 1998; Morrison, \& Gore, 2010; Ybarra et al., 2005). The only dimension of psychological well-being which is not predicted by Internet addiction is personal growth, indicating that there are cases when people who suffer the negative consequences of pathological Internet use can feel they develop their potential through the Internet.

Escalation of concerns was influenced by low Conscientiousness and mediated the effect of the personality trait on well-being. This is an important finding which sheds light on the study of cyberchondria. Conscientiousness describes impulse control connected with self-discipline, planning and dutifulness. Decreased Conscientiousness, which is manifested in impulsivity and lack of direction, is a premise for shifting the focus of an initial symptom-based online health search to a serious medical condition due to escalated worries. Escalation of health concerns as a mediator of the relationship between Conscientiousness and psychological well-being leads to dependence on other people's opinions, helplessness regarding what is happening, decreased sense of purpose and meaning in life, dissatisfaction with certain aspects of the self. These dimensions of psychological wellbeing could be assigned to experiencing high health anxiety, connected with web health search.

As far as the personal trait Agreeableness is concerned, we established that it influenced only one dimension of psychological well-being - positive relations with others, mediated by Internet addiction. No significant indirect effect of Agreeableness on eudaimonic well-being was registered, neither were there any significant effects of Agreeableness on health anxiety and cyberchondria. It was established that antagonism (low levels of Agreeableness) is a predictor for Internet addiction, which in turn leads to aggravated interpersonal relationships. The estimated indirect effect is significant $(\mathrm{ab}=0.0117 ; \mathrm{SE}=0.0079)$ and its confidence interval [0.0005; $0.0324]$ with $95 \%$ probability does not include zero, which indicates significant mediation. The model accounts for $5 \%$ of the variance in the quality of relationships of the user as an indicator of psychological well-being $\left(R^{2}=0.048\right)$.

In summary of the significant results from the series of mediation analyses with personality traits as independent variables, Internet addiction, anxiety aroused by online health information seeking, escalation, and persistence of concerns as mediators, eudaimonic well-being and psychological well-being as dependent variables, the following graphic representation of the interrelatedness of the constructs was created (see Figure 3).

In order to verify the assumption that Internet addiction leads to more extensive Internet use for health information and judgment biases, which in turn lead to higher health anxiety and cyberchondria, three mediation analyses were carried out.

It was established that anxiety aroused by online health information seeking is influenced by Internet addiction through the mediators: judgment biases and extent of online health information seeking (see Table 4). We found significant total and specific indirect effects. The model accounts for $66 \%$ of the variance in health anxiety, stimulated by Internet. 


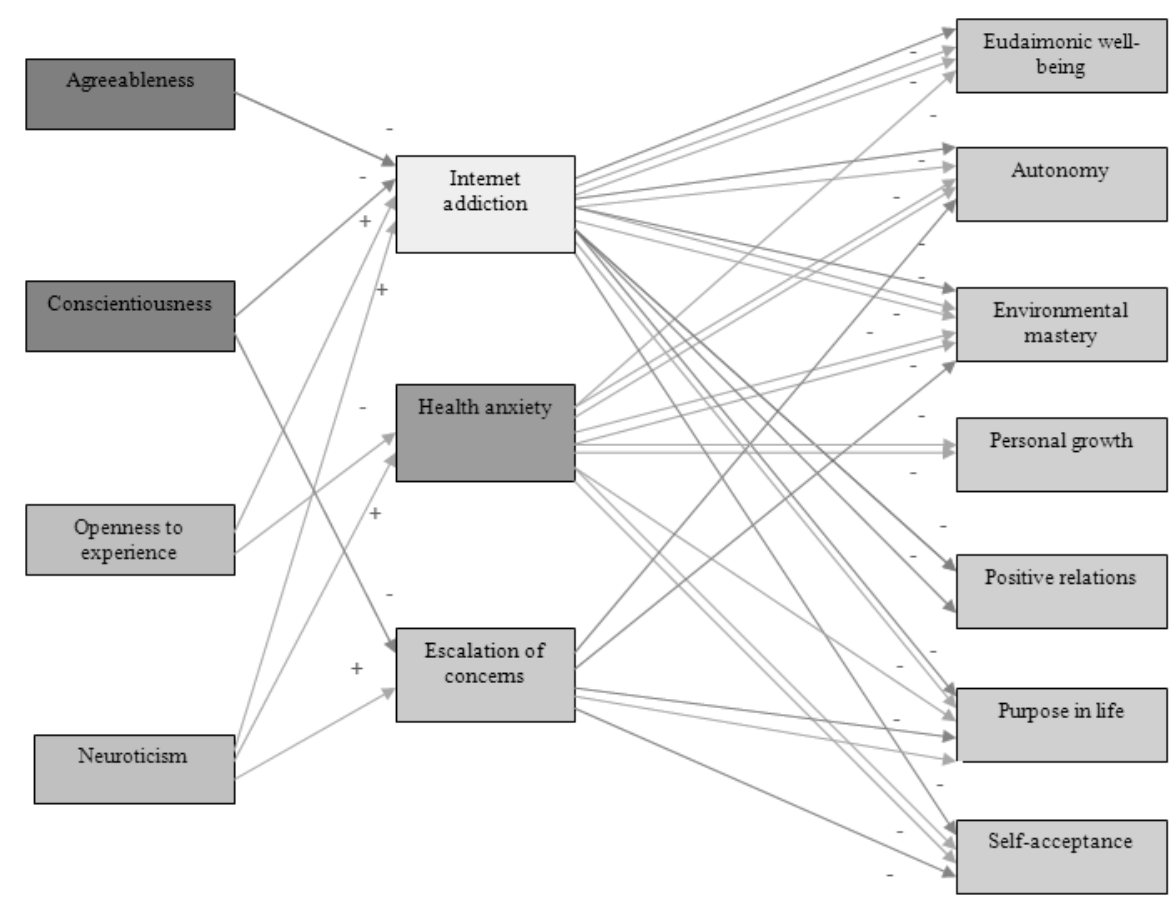

Fig. 3. Graphic model of the mediated influence of personal traits on eudaimonic and psychological well-being with mediators Internet addiction, anxiety aroused by online health information seeking, escalation and persistence of health concerns

Source: Own research.

Tab. 4. Indirect effects from mediation analysis with independent variable Internet addiction and dependent variable anxiety aroused by online health information seeking

\begin{tabular}{|l|c|c|c|c|}
\hline \multirow{2}{*}{\multicolumn{1}{|c|}{ Mediators }} & \multirow{2}{*}{$\begin{array}{c}\text { Estimated } \\
\text { indirect } \\
\text { effect }\end{array}$} & \multirow{2}{*}{$\begin{array}{c}\text { Standard } \\
\text { error }\end{array}$} & & \multicolumn{2}{|c|}{$\begin{array}{c}95 \% \text { confidence } \\
\text { interval }\end{array}$} \\
\cline { 4 - 5 } & & & Lower limit & Upper limit \\
\hline Total indirect effect & 0.0965 & 0.0237 & 0.0496 & 0.1469 \\
\hline Judgment biases & 0.0198 & 0.0062 & 0.0097 & 0.0347 \\
\hline $\begin{array}{l}\text { Extent of online health } \\
\text { information seeking }\end{array}$ & 0.0768 & 0.0208 & 0.0353 & 0.1180 \\
\hline
\end{tabular}

Source: Own research.

Table 4 shows the estimated indirect effects of each of the two mediators as well as the total indirect effect. Their values are positive which indicates the direct ratio of the influences between the variables. The confidence intervals attest the significance of the indirect effects of the two mediators.

On the second step we carried out mediation analysis with a dependent variable escalation of concerns as an indicator of cyberchondria and the same independent variable (Internet addiction) and mediators (judgment biases and extent 
of online health information seeking). Even though, one of the two mediators judgment biases is also an indicator of cyberchondria, it was interesting to investigate whether it influences the other two aspects of cyberchondria - escalation and persistence of concerns. We established significant mediation - there were total as well as specific indirect effects of the two mediators (see Table 5).

Tab. 5. Indirect effects from mediation analysis with independent variable Internet addiction and dependent variable escalation of concerns

\begin{tabular}{|l|c|c|c|c|}
\hline \multirow{2}{*}{ Mediators } & \multirow{2}{*}{$\begin{array}{c}\text { Estimated } \\
\text { indirect } \\
\text { effect }\end{array}$} & \multirow{2}{*}{$\begin{array}{c}\text { Standard } \\
\text { error }\end{array}$} & \multicolumn{2}{|c|}{$\begin{array}{c}\text { 95\% confidence } \\
\text { interval }\end{array}$} \\
\cline { 4 - 5 } & & & Lower limit & Upper limit \\
\hline Total indirect effect & 0.0011 & 0.0003 & 0.0006 & 0.0018 \\
\hline Judgment biases & 0.0006 & 0.0002 & 0.0003 & 0.0011 \\
\hline $\begin{array}{l}\text { Extent of online health } \\
\text { information seeking }\end{array}$ & 0.0005 & 0.0002 & 0.0002 & 0.0010 \\
\hline
\end{tabular}

Source: Own research.

Internet addiction leads to higher probability of judgment biases and to higher extent of using the Internet for health information, which lead to escalation of health concerns. The model explains around $16 \%$ of the variance in the escalation of concerns $\left(R^{2}=0.164\right)$.

Furthermore, we registered similar results in the third case - when we introduced persistence of concerns as a dependent variable (see Table 6). Again, relationships between the variables are positive, which means that users prone to Internet addiction are more inclined to use the Internet for health information and to make mistakes when judging this information, which consequently leads to more persistent health concerns.

Tab. 6. Indirect effects from mediation analysis with independent variable Internet addiction and dependent variable persistence of concerns

\begin{tabular}{|l|c|c|c|c|}
\hline \multirow{2}{*}{ Mediators } & \multirow{2}{*}{$\begin{array}{c}\text { Estimated } \\
\text { indirect } \\
\text { effect }\end{array}$} & \multirow{2}{*}{$\begin{array}{c}\text { Standard } \\
\text { error }\end{array}$} & & \multicolumn{2}{|c|}{$\begin{array}{c}\text { 95\% confidence } \\
\text { interval }\end{array}$} \\
\cline { 4 - 5 } & & & Lower limit & Upper limit \\
\hline Total indirect effect & 0.0014 & 0.0004 & 0.0007 & 0.0002 \\
\hline Judgment biases & 0.0003 & 0.0002 & 0.0001 & 0.0007 \\
\hline $\begin{array}{l}\text { Extent of online health } \\
\text { information seeking }\end{array}$ & 0.0010 & 0.0003 & 0.0005 & 0.0017 \\
\hline
\end{tabular}

Source: Own research.

On the grounds of the mediation analyses, we could conclude that hypothesis four - Internet addiction will have an effect on anxiety aroused by online health information seeking, escalation, and persistence of concerns via mediators - judgment biases and extent of online health information seeking, was completely confirmed.

In summary of the results established from the mediation analyses with independent variable Internet addiction, dependent variables anxiety aroused by 
online health information seeking, escalation, and persistence of concerns, mediators: judgment biases and extent of online health information seeking, the following graphic model, depicting the relationships between the constructs, was created (see Figure 4).

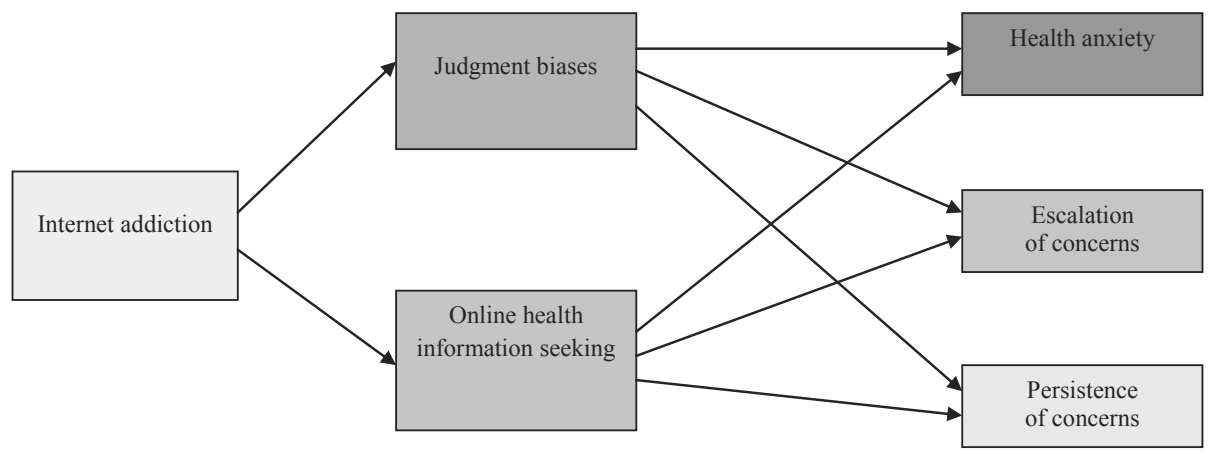

Fig. 4. Graphic model of the mediated influence of Internet addiction on anxiety aroused by online health information seeking, escalation and persistence of health concerns with mediators judgment biases and extent of online health information seeking

Source: Own research.

\section{CONCLUSION}

The findings from the present study, conducted in a Bulgarian context, indicate the following tendencies. In order to investigate the relationships and mutual effects of Internet addiction, cyberchondria, well-being, and personality traits, we carried out regression and mediation analyses.

Neuroticism was established as the main predictor from the Big Five personality traits for Internet addiction, anxiety aroused by online health information seeking, escalation, and persistence of health concerns. Decreased levels of Conscientiousness are associated with Internet addiction and escalation of health concerns following searching for health information online. Moreover, low Openness to Experience is a predictor for anxiety aroused form online health information seeking. The regression analysis did not indicate a significant effect of the traits Extraversion and Agreeableness on Internet addiction and cyberchondria.

On the basis of the results from the mediation analyses, we can conclude that Extraversion does not predict the studied phenomena. Persistence of concerns as an indicator of cyberchondria does not influence significantly any of the measures of well-being. The results suggest that emotional instability is a precondition for Internet addiction, escalation of concerns as an indicator of cyberchondria, and anxiety aroused by online health information seeking, which in turn lead to decreased levels of eudaimonic and psychological well-being. Other than Neuroticism, lack of direction (low Conscientiousness), Openness, and antagonism (low Agreeableness) are also predictors for Internet addiction. We found that people who are unconventional and open to experience are also less likely to feel anxiety as a result from looking for health information online. On the other hand, people who lack direction and discipline are prone to experience escalation of health con- 
cerns when researching the web. Further looking into the relationships between Internet addiction and well-being, we identified the only aspect of psychological well-being that pathological Internet use is not significantly connected with is personal growth. This finding suggests that even Internet addicts could feel that they develop their potential despite the damage they undergo in other aspects of their lives due to excessive use.

It was established that elevated levels of Internet addiction lead indirectly to anxiety aroused by online health information seeking, escalation, and persistence of health concerns and this influence is mediated by judgment biases and extent of online health information seeking. In conclusion, Internet addiction appears to be a predictor for cyberchondria because problematic users tend to use the Internet more for health information and to make cognitive interpretation mistakes of that information towards negative scenarios.

The current study aims at expanding on the research on Internet addiction and cyberchondria by revealing relationships between them, well-being, and personality traits, which can be applied in the social practice when addressing these issues.

\section{REFERENCES}

Amichai-Hamburger, Y., \& Ben-Artzi, E. (2003). Loneliness and Internet use. Computers in Human Behavior, 19(1), 71-80.

Armstrong, L., Phillips, J., \& Saling, L. (2000). Potential determinants of heavier Internet usage, Int. J.Human-Computer Studies, 53(4), 537-550.

Atkinson, N., Saperstein, S., \& Pleis, J. (2009). Using the Internet for health-related activities: findings from a national probability sample. J Med Internet Res, 11(1). Retrieved from http://www.ncbi. nlm.nih.gov/pmc/articles/PMC2762768/

Baumgartner, S., \& Hartmann, T. (2011). The role of health anxiety in online health information search. Cyberpsychology, Behavior, and Social Networking, 14(10), 613-618.

Caplan, S. (2002). Problematic Internet use and psychosocial well-being: Development of a theorybased cognitive-behavioral measurement instrument. Computers in Human Behavior, 18(5), 553-575.

Caplan, S. (2003). Preference for online social interaction. A theory of problematic Internet use and psychosocial well-being, Communication Research, 30(6), 625-648.

Donnellan, M., Oswald, F., Baird, B., \& Lucas, R. (2006). The Mini-IPIP Scales: Tiny-Yet-Effective Measures of the Big Five Factors of Personality. Psychological Assessment, 18(2), 192-203.

Eysenbach, G., \& Kohler, C., (2002). How do consumers search for and appraise health information on the world wide web? Qualitative study using focus groups, usability tests, and in-depth interviews. Brit. Med. J. 324, 573-577.

Goldberg, L. (1999). A broad-bandwidth, public-domain, personality inventory measuring the lowerlevel facets of several five-factor models. Personality Psychology in Europe, 7, 7-28.

Gravatt, S., \& Brown M. (s.a.). Health anxiety and Internet use. Retrieved May 7, 2012, from http:/ / homepage. mac.com/psychresearch/Sites/site2/publications/manuscripts/HealthAnxiety- MJB.pdf.

Greenfield, D. (1999). Virtual addiction: Sometimes new technology can create new problems, The Center for Internet Studies @ Psychological Health Associates. Retrieved September 14, 2012 from http://www.virtual-addiction.com/pdf/nature_internet_addiction.pdf.

Hayes, A. (n.d.). SPSS, SAS, and Mplus Macros and Code - Indirect. Retrieved May 2012, from: http:/ / afhayes.com/spss-sas-and-mplus-macros-and-code.html.

MacKinnon, D., \& Dwyer, J. (1993). Estimation of mediated effects in prevention studies. Evaluation Review, 17(2), 144-158.

Morahan-Martin, J., \& Schumacher, P. (2000). Incidence and correlates of pathological Internet use among college students. Computers in Human Behavior, 16, 13-29.

Morrison, C., \& Gore, H. (2010). The relationship between excessive Internet use and depression: A questionnaire-based study of 1,319 young people and adults. Psychopathology, 43, 121-126. 
Muse, K., McManusa, F., Leunga, C., Meghrebliana, B., Williams, J. (2011). Cyberchondriasis: Fact or fiction? A preliminary examination of the relationship between health anxiety and searching for health information on the Internet. Journal of Anxiety Disorders 26, 189- 196.

Pletneva, N., Cruchet, S., Simonet, M., Kajiwara, M., Boyer, C. (2010). Results from the 10th HON survey on health and medical Internet use. Hon Government Organisation. Retrieved on November, 2013, from http://www.hon.ch/Global/pdf/2010_Internet_use_Analysis.pdf.

Preacher, K., \& Hayes, A. (2008). Asymptotic and resampling strategies for assessing and comparing indirect effects in multiple mediator models. Behavior Research Methods, 40(3), 879-891.

Salkovskis, P., Rimes, K., Warwick, H., \& Clark, D. (2002). The Health Anxiety Inventory: development and validation of scales for the measurement of health anxiety and hypochondriasis. Psychological Medicine, 32, 843-853.

Silgidgyan, H., Karabeliova, S., \& Zankova, E. (2008). Empirical meeting of two traditions in the study of psychological health. Bulgarian Journal of Psychology, Fifth National Congress on Psychology. Sofia: East-West.

Sobel, M. (1982). Asymptotic confidence intervals for indirect effects in structural equation models. Sociological Methodology, 13, 290-313.

Valkenburg, P., \& Peter, J. (2007). Online communication and adolescent well-being: Testing the stimulation versus the displacement hypothesis. Journal of Computer-Mediated Communication, 12, 1169-1182.

Waterman, A., Schwartz, S., Zamboanga, B., Ravert, R., Williams, M., Bede Agocha, V., Su Yeong Kim, \& Donnellan, M. (2010). The questionnaire for eudaimonic well-being: Psychometric properties, demographic comparisons, and evidence of validity. The Journal of Positive Psychology, vol. 5, 41-61.

White, R., \& Horvitz, E. (2009b). Experiences with Web Search on Medical Concerns and Self Diagnosis. AMIA Anпu Symp Proc. 696-700.

White, R., \& Horvitz, E. (2012). Studies of the onset and persistence of medical concerns in search logs. ACM SIGIR, 265-274.

White, R., \& Horvitz, E. (2009a). Cyberchondria: studies of the escalation of medical concerns in Web search. ACM Transactions on Information Systems, 27(4),1-37.

Widyanto, L., \& McMurran, M. (2004). The psychometric properties of the Internet addiction test, Cyber Psychology and Behavior, 7, 443-450.

Ybarra, M., Alexander, C., \& Mitchell, K. (2005). Depressive symptomatology, youth Internet use, and online interactions: a national survey. Journal of Adolescent Health 36, 9-18.

Ybarra,M., \& Suman, M. (2006). Help seeking behavior and the Internet: A national survey. International Journal of Medical Informatics, 75, 29-41.

Young, K. (1996). Internet addiction: the emergence of a new clinical disorder, Cyber Psychology and Behavior, 1(3), 237-244.

Young, K. (1998). Caught in the Net. New York: John Wiley \& Sons.

Morahan-Martin, J. (2005). Internet abuse addiction? Disorder? Symptom? Alternative explanations? Social Science Computer Review. 23(1). 39-48.

Young, K. (2007). Cognitive behavior therapy with Internet addicts: treatment outcomes and implications. Cyberpsychology Behavior, 10(5), 671-679.

Young, K., \& Rodgers, R. (1998). The relationship between depression and Internet addiction. CyberPsychology \& Behavior, 1(1), 25-28. 